\title{
Factors influencing staff nurses' decisions for non-documentation of patient response to analgesia administration
}

\author{
MARY NIES ALBRECHT PhD, RN \\ Postdoctoral Research Fellow, University of Michigan, Center for Nursing Research, Ann \\ Arbor, MI, USA \\ JEANETTE E. COOK MA, CNA, RN \\ Director of Nursing, Research and Support, Elmhurst Memorial Hospital, Elmhurst, IL, USA \\ MARVEL JEAN RILEY MSN, RN \\ Clinical Nurse Educator, Extended Care, Hines Veterans Administration, Hines, IL, USA \\ VICKI ANDREONI MS, RN \\ Clinical Specialist, Pediatric Oncology, University of Chicago Hospitals, Chicago, IL, USA \\ Accepted for publication 12 March 1992
}

\section{Summary}

- The purpose of this descriptive field study is to determine what factors influence staff nurses' decisions for non-documentation of patients' response to analgesic administration.

- The study, based on Herbert Simon's descriptive model of decision making, has two components: (a) to determine staff nurses' perceptions of the factors that influence their documentation as well as how frequently they document analgesic administration and (b) to determine the actual frequency of nurses' documentation.

- Data collected from 67 staff nurses using a questionnaire designed for this study and through an audit of 65 patients' charts allowed comparison of nurses' perceptions with their actual practice.

- Analysis involved both quantitative and qualitative approaches.

- The results of the study have implications for nurse educators and nurse administrators.

Keymords: analgesia administration, decision making, documentation, outcomes.

\section{Introduction}

Nursing's status as a profession is a long-debated issue, and continues to be disputed by many authorities today.

Correspondence: Dr Mary Nies Albrecht, 5504 Groveside Lane, Rolling Meadows, IL 60008, USA.

This article was mritten while Dr Albrecht, Ms Riley, and Ms Andreoni were at Elmhurst College, IL, USA.
'Nursing, like other occupations seeking to establish themselves as professions, is experiencing concerns for the development of a service orientation, the continual growth of a scientific base from which members practice, and the evolution of a fairly distinct body of knowledge that separates nursing from other professions' (Polit \& Hungler, 1983). Examining the realm of decision making in daily nursing practice would serve to clarify the autonomous role of nursing. McKay (1983) pointed out 
that many nurses feel that they do not make independent decisions, or they see their decisions as less important than medical or administrative decisions.

The nursing process was introduced in the United States in the $1950 \mathrm{~s}$, and since that time has become widely accepted as the basis for nursing practice in this country. According to Rodgers (1976), the two main components of the process are the interpersonal and the problem-solving processes. In order to function as a professional nurse, one must have the ability to gather data, plan a course of action, implement the plan, and evaluate its outcome. In other words, the nurse must be able to recognize the client's needs and make decisions which are based on sound priorities (Hollingworth, 1986).

The decisions nurses make tend to focus on the interaction between the client's level of functioning and the day-to-day demands of the environment, and are not necessarily limited to the care prescribed by the physician (Prindham \& Hansen, 1985). Nurses need to realize the existence and importance of these decisions through explicit and consistent documentation. Additionally, documentation is the nurse's legal responsibility, as lack of it could be considered evidence of negligence (Cushing, 1982).

The decision-making process as it relates to nursing practice has been described by a number of authors (Grier, 1976; del Bueno, 1983; Tanner, 1983; Bolton, 1984). In general, the complex process of clinical decision making involves:

- identifying the appropriate cues;

- interpreting the cues accurately;

- considering all available options which includes reasons to do or not do a particular activity;

- selecting an intervention, action or response.

Evaluation of the intervention or action is critical and should not be overlooked. This essential step will give the nurse valuable information about the effectiveness of the selected action or response and will influence future decisions. The terms clinical problem solving, clinical judgement, and clinical decision making have been used somewhat interchangeably in the literature. For the purposes of this paper, the term clinical decision making will be used to refer to the process described above.

\section{Review of the literature}

Tanner (1983) provided a comprehensive review of research done in the area of clinical decision making. One finding of interest is that thorough cue identification and accurate interpretation of the cues was correlated with accurate diagnoses. Hollingworth (1986) further indicated that good decision making is related to the nurse's ability to predict likely outcomes of interventions. This means that the nurse must collect sufficient data post-intervention to evaluate the effectiveness of the nursing action.

Del Bueno (1983) identified practical experience, availability of decision-making opportunities, and the nurse's educational preparation as factors important in arriving at sound clinical decisions. Bolton (1984) agreed that decision making improves with practice. She further suggested that, 'environmental stimuli, the nature of the feedback, the complexity of the information-processing and decisionmaking functions, and the nature of the task' are factors which contribute to the ability to make a clinical decision.

Corcoran (1986) studied the decision-making process of novice and expert nurses when carrying out tasks of varying complexity. Her findings indicated that the decision-making processes used varied across tasks and were not necessarily systematic. Again, clinical experience appeared to be a positive factor as expert nurses were able to generate better (care) plans than novices.

While these studies reflect some agreement as to the process and factors necessary to make well-grounded clinical decisions, they give no attention to the actual process of evaluating the outcomes or reasons for their decisions. Concentrating on a particular clinical problem, such as pain relief, provides slightly more information.

The importance of making accurate assessments of the client in pain and the specific nursing interventions used to alleviate pain are well documented (Bourbonnais, 1981; Bagley et al., 1982; Sheredy, 1984; Wells, 1984). Much less is written about the nurse's evaluation of the intervention's effectiveness.

Bourbonnais (1981) developed a 'pain ruler' to increase the accuracy of assessment of the patient in pain, with the intention that this would also result in improved documentation and implementation of pain relief measures. She noted that accurate charting of the client's pain is an important method of nurse-to-nurse communication and can aid in determining the cause of pain. However, she did not indicate whether use of the tool produced the expected improvement in documentation.

Bagley et al. (1982) implemented a pain management programme which included an evaluation of documentation of the patient's response to analgesia. While the nurses habitually reported the type of drug, dosage, time, and route, and noted the patient's need for medication, they did not consistently document the response to the medication. When the response was documented, it was done in general terms such as 'effective', 'some relief', 'with relief,' or 'with effect'. The factors influencing lack of documentation were not investigated. 
Fogelsong (1983) studied the impact of an educational programme on managing post-operative pain on the frequency of administration and subsequent documentation of analgesics by staff nurses. Prior to the inservice training, $33 \%(5 / 20)$ of charts audited contained a statement relating to the client's response to the analgesic. Data collection after the programme, which was not restricted to those nurses attending the seminar, showed the incidence of documentation to be $70 \%(14 / 20)$ of charts audited.

It is evident that reasons which influence nurses' decisions to document client response to analgesia are missing from the literature. Identification of these reasons is important. A description will alert educators to the possible need for increased emphasis on the evaluation portion of the nursing process. In addition, interventions to increase documentation of patient response to analgesia can be formulated once the influencing variables are uncovered. Consistent charting of patient outcomes improves communication between nurses, and ultimately, patient care, as nurses individualize their care based on the success or failure of the interventions.

The purpose of this study was to examine the reasons why nurses decide not to document the response of acute adult surgical patients to analgesia administration and to determine their self perception of prn analgesia administration documentation.

\section{Conceptual framework}

Decision making is defined as 'the act of choosing among alternatives' (Lancaster \& Lancaster, 1982). Decisions are made because a problem exists in the attainment of goals. Nurses are confronted with the task of making personal, administrative, and collaborative decisions in their daily practice. Because the practice issues nurses face are potentially life-threatening, it is not desirable or even practical to base decisions on hunches, intuition, or past experience. Each nursing situation must be considered individually in the light of the resources, constraints, and circumstances before reasons, actions, or options are decided.

The descriptive mode for decision making introduced by Herbert Simon accommodates the types of reasons nurses use to make decisions. The model assumes that decision makers are rational people who must often decide issues without the benefit of a complete data base. Issues of time, money, and people frequently preclude comprehensive data collection. Further, the model assumes that problems may not necessarily be clear or accurately defined. Therefore, decisions must be made on the basis of known reasons or accessible information (Simon, 1976).
Under the premise of the descriptive model, the decisions that a nurse makes may not be ideal, but are acceptable in view of the reasons to do or not to do a particular activity based on the circumstances. 'The difficulty encompassed in making a decision depends on a variety of reasons, including the number and quality of the alternatives, risks, and the interaction effects.' (Lancaster \& Lancaster, 1982)

\section{Methodology}

This study investigated the reasons influencing staff nurses' decisions to not document patient response to prn analgesic medications. Other variables considered were actual documentation of patient responses to prn analgesic medications, perceptions of the importance of documenting patient response and estimated percentage time subjects documented the information. Demographic data were also collected and reported.

The institution utilized in this study was a 431-bed, Chicago-suburban, acute-care hospital. Patients included in the study were housed in a 50-bed medical/surgical unit, a 44-bed surgical unit, and a 33-bed obstetric-gynaecological unit. These units were chosen because most surgical patients admitted are placed there.

All nurses in the three units received a letter asking them to participate. They were assured that data would be anonymous and individuals would not be identified. Eighty-one letters, consent forms (Appendix 1), and questionnaires (Appendix 2) were distributed. The consent forms were coded so that each nurse, once consenting to participate in the study, was known only by a code number. Returned consent forms and questionnaires were separated by a research assistant not connected to the research study. Seventy-six were returned (response rate: $94 \%$ ) of which 71 were analysed (two returned the questionnaire unanswered; three others were not decipherable).

Two data collection tools were constructed. The investigators constructed a questionnaire (Appendix 2) to collect qualitative, quantitative, and demographic information. For convenience, the questionnaire was piloted in four nearby acute-care community hospitals and one large Veteran's hospital. A total of 25 staff nurses participated in this test for content validity and interrater reliability. Following the pilot test several changes and/or clarifications were made to the questionnaire.

The first part of the study was a retrospective analysis of actual documentation of analgesic response. A tool (Appendix 3) was developed to collect data retrospectively to determine actual practice, so that actual practice could be compared with practice described in Appendix 2. To 
decrease contamination of the data, a research assistant was utilized to collect this data from the patients' charts.

Data was collected for 1 month from all patients admitted for surgery with a length of stay of at least 3 postoperative days. This information was collected prior to the distribution of the questionnaire.

\section{Data analysis}

Descriptive statistics were used to analyse the data collected on the questionnaire completed by the subjects and the actual documentation of all prn analgesic medication administered to immediate post-operative patients.

\section{FACTORS INFLUENCING NON-DOCUMENTATION OF}

PATIENT RESPONSE TO PRN ANALGESIC MEDICATION

The subjects selected from a predetermined list those reasons that influenced them in a given situation to not document patient response to prn analgesic medication administration (Table 1).

The single reasons identified by the subjects influencing their decision-making process were:

- medication given for another registered nurse;

- medication given at hour of sleep;

- past hospitalization with listing of drug abuse;

- unusual response such as allergic;

- other charting by a nurse indicating increase or decrease in comfort;

- usually do not document response because action is to alleviate discomfort, therefore, document when medication is not effective.

The factor of unit activity ranked the highest. This might be expected because of high activity level on surgical units which according to Herbert Simon's (1976) model influences the decisions nurses make.

Table 1 Major factors influencing non-documentation of patient response to analgesic medication administration

\begin{tabular}{ll}
\hline Rank of facts by importance & Per cent \\
\hline Unit activity (busy, hectic, slow, patient availability) & 18 \\
Frequency of pain medication requested & 16 \\
Medication given at change of shift & 15 \\
Forget to document/chart & 13 \\
Mental alertness of patient & 12 \\
Lack of time & 8 \\
Type of medication & 7 \\
Patient diagnoses & 6 \\
Age of patient & 6 \\
\hline
\end{tabular}

Frequency of pain medication requested ranked second and it is assumed that nurses were using a decision-making process in determining documentation. Results might be affected by the census at time of study and staffing patterns at the specific institution.

\section{RECENT CIRCUMSTANCES INFLUENCING SUBJECT'S} DECISION FOR NON-DOCUMENTATION OF PATIENT'S RESPONSE TO PRN ANALGESIC MEDICATION

Major responses of the subjects were categorized and ranked (Table 2). Two subjects responded to each of the following:

- try to chart-if only to say patient appears to be sleeping;

- do not make conscious decision to chart or not to chart patient response to anything;

- negative response or reaction only time need to document;

- strength of medication is more than patient needs;

- patient gives different responses to different nurses;

- receiving placebos.

Subjects responded with a wide range of responses varying from utilizing assessment, to making decisions, to remembering that a nursing audit had been done on the subject in the past.

Others singly responded with:

- part of patient care-a doctor's order that is to be carried out;

- documented patient able to obtain relief;

- gave new analgesic and felt response important;

- blood pressure low and patient in severe pain;

- lack of time;

- don't remember;

- do not see patient again until requests more pain medication;

- patient on pain medication for extended period of time;

- patient becoming combative and disorientated from pain medication. Two responses were not relevant.

The responses give insight into nurses' reasons for documentation and what they were thinking and indicate that nurses do use a decision-making process to determine when to document or not to document patient response to analgesic medication administration. Subjects also used habit when deciding to document as indicated in the response 'always document'. Institutional policy and awareness of need to document prn analgesic medications also appeared to influence the decision to document. Nursing administration can utilize this knowledge in future planning. 
Table 2 Major response to specific circumstances influencing decision to not document patient response to prn analgesic medication

\begin{tabular}{llc}
\hline & \multicolumn{2}{l}{ Subjects } \\
\cline { 2 - 3 } Subject responses & Number & Per cent \\
\hline Frequent use of pain medication such as every 2-3 h & 9 & 13 \\
Always document & 7 & 10 \\
Recent surgical patient or first time receiving pain medication & 6 & 8 \\
Recently became aware important to chart patient response & 4 & 6 \\
$\quad$ because of nursing audits & & \\
Patient goes to sleep after pain medication-assume pain relieved & 4 & 6 \\
Forget or assume relief if no complaint & 3 & 4 \\
No response & 12 & 17
\end{tabular}

IMPORTANCE OF DOCUMENTING SURGICAL PATIENT'S RESPONSE TO PRN ANALGESIC MEDICATION

Using a scale ranging from 'not important' to 'extremely important', subjects ranked the importance given to documenting surgical patient's response to prn analgesic medication. Fifty-two per cent of the subjects ranked documentation as 'important' while $33 \%$ of the subjects ranked it as 'extremely important' (Table 3). Factors influencing nurses in their decision-making process of ranking the importance of documentation were categorized and ranked. Eighty-six per cent of the subjects thought documentation of prn analgesic medication is 'important' or 'extremely important' which indicates that theoretically they have been taught the importance of documentation and remember it.

\section{ANALYSIS OF 'RANK OF IMPORTANCE' RESULTS}

The results of the subjects' major responses as to why they ranked importance as they did were grouped into categories, percentages determined, and were ranked (Table 4). Single responses listed were:

- each patient has different threshold for pain;

- most cases patients automatically get relief from pain medication - expected response therefore repeated and becomes repetitious;

Table 3 Subjects rank of importance of documenting surgical patients response to prn analgesic medication

\begin{tabular}{lc}
\hline & Per cent \\
\hline Not important & 3 \\
Somewhat important & 11 \\
Important & 52 \\
Extremely important & 33 \\
No answer & 1 \\
\hline
\end{tabular}

- not good use of time;

- patient has specific comments about medication relief;

- when medication given it is a 'given' that must be charted;

- staff nurse doesn't look at chart.

Responses may be due to basic knowledge about the expected action of medication level of reinforcement within the institution of expectation of documentation and nurses' feelings about repeating the same information. The philosophy of the individual nurse may be another factor utilized in the decision-making process when deciding to document prn analgesic medication.

\section{ESTIMATED PER CENT OF TIMES SUBJECT DOCUMENTED PATIENT RESPONSE TO PRN ANALGESIC MEDICATION}

The range of estimation of times that each subject thought they documented patient response to prn analgesic medication was from $91-100 \%$ to under $40 \%$ (median: $71-80 \%$; Table 5).

Data results may relate to the age of the subjects and to the basic nursing educational preparation of the subjects. Much more emphasis has been placed on documentation of patient responses to analgesic medication in recent years due to legal implications and cost containment elements.

ACTUAL DOCUMENTATION OF PRN ANALGESIC MEDICATION

Analgesic prn medications were administered a total of 644 times by 129 nurses to 65 immediate post-operative patients in 30 days. Three-hundred and four $(47 \%)$ of those medications were documented and $340(53 \%)$ medication administrations were not documented.

Patients may have been temporarily located in an intensive-care unit or been exposed to a float nurse for care, therefore having medication documentation by 


\begin{tabular}{lll}
\hline Responses & Number & Per cent \\
\hline $\begin{array}{l}\text { Effectiveness of medication and/or best way to know patient } \\
\quad \text { responding }\end{array}$ & 30 & 42 \\
$\begin{array}{l}\text { Important due to patient being immediately post-operative } \\
\text { Document if medication doesn't help }\end{array}$ & 6 & 9 \\
Enables physician to change medication if not effective & 5 & 9 \\
No response & 4 & 6 \\
Responsibility of nurse to see that patient comfortable & 3 & 4 \\
Too busy 'just doing basics' & 3 & 4 \\
To communicate effectiveness to others & 2 & 3 \\
Over medication can cause problems & 2 & 3 \\
Too much or too little medication makes difference in recovery & 2 & 3 \\
Alerted to other problems occurring with patient & 2 & 3 \\
\hline
\end{tabular}

Table 4 Responses to 'why' importance ranked as recorded nurses other than those nurses completing the questionnaire. After deleting the intensive care and float nurses' medication administrations, there were a total of 496 times that medication was administered by nurses permanently assigned to the three units and completing the questionnaire. Of the 496 times medication was administered, 232 $(47 \%)$ administrations were documented and $264(53 \%)$ were not documented.

It is interesting that the percentage of documentation of medication administration is the same for all nurses and those nurses who completed the questionnaire which suggests that the nurses within this institution generally document medication administration about the same percentage of time.

\section{Demographics}

Demographic information from the questionnaire was tabulated for each subject in each age and summarized (Table 6).

Table 5 Estimated times subjects documented patient response to prn analgesic medication

\begin{tabular}{ll}
\hline Per cent of time & Per cent of subjects \\
\hline $91-100$ & 16 \\
$81-90$ & 29 \\
$71-80$ & 20 \\
$61-70$ & 10 \\
$51-60$ & 9 \\
$41-50$ & 3 \\
Under 40 & 14 \\
\hline
\end{tabular}

\section{AGE}

The age range of the subjects was $22-64$ years with $51 \%$ of the participants under 40 years (mean age: 41 years). The age groups are delineated as follows: $20-24(6 \%) ; 25-29$ $(19 \%) ; 30-34(13 \%) ; 35-39(11 \%) ; 40-44(13 \%) ; 45-49$ $(11 \%)$; $50-54(8 \%) ; 55-60(17 \%)$; over $60(3 \%)$. No response was given by $7 \%$ and there were two responses, such as 'who cares! I do my work!' and “' 29 ” and holding.'

\section{EMPLOYMENT}

Sixty-five per cent of those surveyed were currently employed full time, while $35 \%$ were employed part time. Subjects working part time were employed from 20 to $48 \mathrm{~h}$

Table 6 Demographics

\begin{tabular}{ll}
\hline & Per cent \\
\hline Employment & \\
Full time & 65 \\
Part time & 35 \\
Educational background & \\
Diploma & 54 \\
ADN & 30 \\
BSN & 17 \\
& \\
Years at institution of employment & \\
$0-5$ & 38 \\
$5-10$ & 24 \\
$11-15$ & 12 \\
$16-20$ & 20 \\
$>20$ & 6 \\
No response & 7 \\
\hline
\end{tabular}


per 2-week period and $52 \%$ of the subjects were employed part time 40 or more hours in a 2 -week period.

\section{YEARS OF WORK EXPERIENCE}

The total number of years of professional work experience varied considerably with the most having less than 5 years' experience $(32 \%) ; 18 \%$ had $5-10$ years; $9 \%, 12-15$ years; $16 \%, 16-20$ years; $4 \%, 21-25$ years; $12 \%, 26-30$ years; and $9 \%$, more than 30 years.

\section{YEARS AT THE INSTITUTION WHERE STUDY CONDUCTED}

The range was also very wide for this category: from $1 \cdot 5$ months to 29.5 years, with the mean being 9.4 years; $38 \%$, less than 5 years; $24 \%, 6-10$ years; $12 \%, 11-15$ years; $20 \%, 16-20$ years; $6 \%$, over 20 years; and $7 \%$, no response.

\section{EDUCATIONAL BACKGROUND}

The participants were asked to indicate the school in which they obtained their basic education. The largest percentage, $54 \%$, attended a diploma programme, $30 \%$, associate degree, and $17 \%$, baccalaureate programme.

Eight per cent of the subjects had a higher degree with one person having an MA in counselling and five people having a Bachelor's degree; three had a BSN; one a BS in biology and one a BSA.

\section{Significance and implications}

The findings and conclusions of this study raised serious questions about a number of aspects influencing the decision-making process the nurses utilized to document patient response to prn analgesic medication and administration. Prindham \& Hansen's (1985) indication that the decisions nurses make is an interaction between the patient's level of functioning and day-to-day demands on the units was supported by this study. Nurses ranked unit activity as the highest factor influencing their decision to document patient response to prn medication which suggests that the documentation of medication received a lower priority than many other nursing unit activities. Statements such as 'assume relief if no complaint', 'patient goes to sleep after pain medication therefore assume relief', and no response of $17 \%$ of the subjects indicates a lack of feeling of importance of this activity. Frequency of pain medication requested ranked second as a factor influencing the nurse's decision-making process regarding documentation, indicating that patients who complained the most received the nurse's attention and one way the nurse responded was to document the response observed in the patient.

The fact that $50 \%$ of the subjects had more than 10 years' experience $(21 \%$ had more than 26 years' experience) may have influenced the results of this study. In the past, nursing education and nursing services have not emphasized documentation of patient response of prn analgesic medications as heavily as in recent years, therefore, the nurse's basic education may have influenced their decision-making process regarding documentation of patient response to prn analgesic medication. Del Bueno (1983) supports nursing education preparation as a factor in arriving at sound clinical decisions but other factors she cited such as practical experience and availability of decision making were not supported in this study.

Nurses perceived themselves as documenting patient response to analgesic medication much more frequently than they actually did. Sixty-five per cent of the nurses estimated that they documented patient response to prn analgesic medication more than $70 \%$ of the time while they actually documented patient response $47 \%$ of the time. The discrepancy of perception and actual performance leads to the question of how this incongruence influences the decision-making process of the nurse. In light of the conceptual framework, this discrepancy can be related to the nurses attainment of goals for the day. The nurse may decide that other responsibilities take priority or nondocumentation is acceptable based on the circumstances and the conditions of the other patients on the units.

The findings of this study have several implications for nursing. Because many subjects did not perceive the importance of documenting patient response to prn analgesic medication, as illustrated by ranking or actual performance, nurse educators must learn how the nurse determines this decision of performance and what factors influence the nurse's decisions regarding the subject. It is important that nurse educators stress the importance of documenting patient's reponse to prn analgesic medication and that staff education departments continue to stress the importance of this act in the place of employment. Nursing Service Adminstrators should compare the current policy statement with the practice observed in this study, then determine which is appropriate, and make changes so that policy and practice coincide.

Increased documentation of patient response to prn analgesic medication would result in decreased administration of analgesic medication that is ineffective, increased comfort of the patient, increased safety of medication administration, and decreased cost of health care. Nursing is becoming a more autonomous profession each day and is 
being held increasingly accountable-legally and professionally. Nursing is also accountable for decreasing healthcare cost and their decision-making skills definitely affect both of the above. Once a decision is made documentation must occur.

Limitations of this study include the use of only one institution and an older population educated when specific documentation was not considered as important as today. Nurses in the past also made relatively few decisions compared to today's expectations. Another limitation is the nature of the data collection for importance of documentation. Self-reports of the importance of documentation of prn analgesic administration may be inflated due to the fact that nurses consciously know that they should document patient response to analgesia, however, in light of the conceptual framework, they consider the risks low, therefore, do not consistently document. Replications of this study in various institutions would provide more information on the nature of discrepancy between perceived and actual documentation.

Research in the use of the decision-making process in the clinical setting and a deliniation of factors that affect the decision-making process is needed. Research is also indicated if the ranking of the importance of an act in relation to actual performance and how, and if, it affects the decision-making process. Future studies should consider using a control group on one nursing unit and another group on a different nursing unit that has received an educational intervention on the importance of documentation, the rationale for, and benefits to patient, nurse, institution, and society. Comparison of the results from both units initially and at 6 months and 1 year intervals would determine those effects and duration of the intervention.

\section{Acknowledgment}

This study was supported by a grant from the Lizzadro Family of Elmhurst, IL, USA.

\section{References}

Bagley C.S., Falinski E., Garnizo N. \& Hooker L. (1982) Pain management: a pilot project. Cancer Nursing 5, 191-199.

Bolton J.C. (1984) Educating professional nurses for clinical practice. Nursing and Health Care 5(7), 385-389.

Bourbonnais F. (1981) Pain assessment: development of a tool for the nurse and patient. Fournal of Advanced Nursing 6, 277-282.

Corcoran S.A. (1986) Task complexity and nursing expertise as factors in decision making. Nursing Research 35(2), 107-112.

Cushing M. (1982) Gaps in documentation. American fournal of Nursing 12, 1899-1900. del Bueno D.J. (1983) Doing the right thing: nurses' ability to make clinical decisions. Nurse Educator 8(3), 7-11.

Fogelsong D.H. (1983) The impact of a staff development offering on nursing practice. The fournal of Continuing Education in Nursing 14(6), 12-16.

Grier M.R. (1976) Decision making about patient care. Nursing Research 25(2), 105-109.

Hollingworth S. (1986) The nursing process: implications for curriculum planning. Fournal of Advanced Nursing 11, 211-216.

Lancaster W. \& Lancaster J. (1982) Rational decision making: managing uncertainty. Journal of Nursing Administration 12, 23-28.

McKay P.S. (1983) Independent decision making: redefining professional autonomy. Nursing Administration Quarterly 7(4), 21-30.

Polit D. \& Hungler B. (1983) Nursing Research: Principles and Methods, 2nd edn. J.P. Lippincott, Philadelphia.

Prindham K.F. \& Hansen M.F. (1985) Nursing and medicine: complimentary modes of thought and action. Public Health Nursing 2(4), 195-201.

Rodgers J.A. (1976) Today's preparation for tomorrow's practice. Fournal of Advanced Nursing 1, 311-322.

Sheredy K. (1984) Factors to consider when assessing response to pain. MCN The American Journal of Maternal Child Nursing 9(4), $250-252$.

Simon H.A. (1976) Administrative Behavior, 3rd edn. Free Press, New York.

Tanner C.A. (1983) Research on clinical judgement. In Review of Research in Nursing Education (Holzemer W.L., ed.). Slack, Inc, Thorofare, NJ, pp 3-23.

Wells B. (1984) Responses to acute pain and nursing implications. fournal of Advanced Nursing 9(1), 51-58.

\section{Appendix 1 Consent form-agreement to participate}

I agree to participate in the Staff Nurse Decisions to Document Surgical Patient Response to prn Analgesic Medication Project being conducted by the hospital Department of Nursing and College Center for Education. I understand that I may withdraw from this project at any time.

I understand that all the information I provide will be kept in strictest confidence and data reported will be anonymous.

Participant's signature

Participant's name

Code number 
Appendix 2 Staff nurse decision to document surgical patient response to prn analgesic medication-questionnaire

Part I. We're conducting an opinion poll and we'd like to know your viewpoint on the following questions:

1. What factors influence you in a given situation to document or not document patient response to analgesic administration? 'Tick as many as apply:

$\square$ unit activity (i.e.

forget to document/or busy, hectic, slow, chart chart access, patient availability)

patient diagnosis

$\square$ frequency of pain med requested

age of patient

$\square$ mental alertness of patient

lack of time

type of medication

medication given at change of shift
Preparation

Basic nursing:
ADN
Diploma

BSN

Year

attained Institution

Highest degree:
BSN
MSN
PhD
OTHER

Full time:

Shift

Float

Part time:

Hours/pay period

Age

Registry

Appendix 3 Patient response to analgesic administration worksheet

Patient record

Hospital no.

1. How many times did the patient receive analgesic medication?

2. How many times were the results (patient response) to the medication documented?

Medication sheet/nurses notes

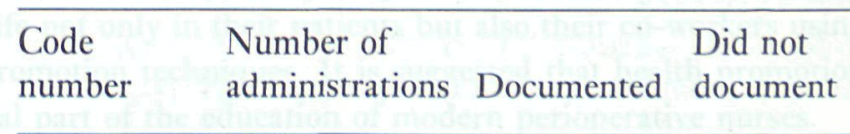

$(1=$ not important, $2=$ somewhat important, 3 = important, 4 = extremely important)

Rank no.__ Why?

4. If you had to estimate in your overall practice the percentage of times you document the patient's response to pain medication, what would your response be?
$91-100 \%$ (of the time)
$51-60 \%$
$81-90 \%$
$41-50 \%$
$71-80 \%$
under $40 \%$
$61-70 \%$

Part II. Demographics

Code Number:

Unit:

Total documented

Total not documented

Total administration

Years in practice:

Years at this hospital 
This document is a scanned copy of a printed document. No warranty is given about the accuracy of the copy. Users should refer to the original published version of the material. 